\title{
La belleza de lo impermanente como proyecto humanista: un ensayo sobre los orígenes de la estética japonesa y sus raíces en la filosofía alemana
}

\author{
ALEJANDRO BÁRCENAS \\ Universidad de Hawai (Estados Unidos) \\ "La verdadera naturaleza de la concepción filosófica \\ de lo bello debe contener, reconciliada dentro de sí, \\ universalidad metafísica y la determinación de lo \\ particular." \\ G.W.F. Hegel, Lecciones de Estética (1826) \\ "Para poder explicar la cultura japonesa debemos \\ recurrir a su propia historia... al mismo tiempo \\ debemos examinar en qué sentido la cultura japonesa \\ puede ser considerada parte de la cultura global y \\ cómo puede desarrollarse como tal."
}

Nishida Kitarô, Problemas de la culfura japonesa (1938)

Durante el siglo xX El. ESTUdio de la estética japonesa ${ }^{1}$ ha oscilado entre la realización de investigaciones culturales de alto nivel y la tendencia al et-

1 Por "estética japonesa" se entenderán las investigaciones realizadas por los filósofos japoneses que tomaron la cultura y las artes del Japón como el objeto principal de sus obras. No se incluirán en el presente ensayo los trabajos realizados en otros campos más especulativos de la estética, como en el caso de las aproximaciones psicológicas y fenomenológicas a la experiencia y apreciación artística, las cuales fueron emuladas en Japón siguiendo las líneas del pensamiento de Edmund Husserl y Theodor Lipps. 
nocentrismo radical. La nube del nihonjinron ${ }^{2}$, aparato ideológico de dudoso sustento conceptual al servicio de la política de extrema derecha que dominó a finales de los años treinta, ha oscurecido y cubierto de sospecha todas las áreas de conocimiento dedicadas al Japón incluyendo, desde luego, la filosofía del arte.

Tras la Segunda Guerra Mundial, el nihonjinron se convirtió en un género literario cuyo objetivo era crear una doctrina con el cometido de exaltar el carácter único del sentimiento cultural y étnico de los pobladores del archipiélago japonés. La industria de exaltación se desarrolló vertiginosamente en los años siguientes y, desde entonces, ha existido la tentación de olvidar la honestidad que generalmente guía la labor académica para sustituirla por la obcecada búsqueda de una expresión verdaderamente autóctona y aislada de la realidad japonesa. Su influencia continúa inclusive hoy en día y ha ejercido su peligroso poder de convencimiento sobre múltiples generaciones de japoneses en el modo en el que éstos perciben y afrontan su propia cultura e historia ${ }^{3}$.

Pero, a pesar del nihonjinron y las duras y obsesivas críticas de autores como Peter Dale, a lo largo del siglo XX se han realizado serios y rigurosos esfuerzos dentro del ambiente filosófico japonés. Su meta ha sido inquirir sobre las raíces culturales de una cadena de islas que,-aunque influenciadas por muchas otras culturas de su alrededor-, sin embargo, llegaron a configurar una identidad estética original.

\section{LA APERTURA A OCCIDENTE}

En 1853 un acontecimiento crucial sucedido en la bahía de la ciudad conocida entonces como Edo, dio inicio a una serie de eventos que transformaron radicalmente Japón. Matthew Calbraith Perry (1794-1858), capitán de la marina de los Estados Unidos, arribó a estas costas demandando la apertura de los puertos a los barcos mercantes extranjeros. El 14 de julio del mismo año, Perry presentó a los oficiales del gobierno japonés una carta del presidente Millard Fillmore solicitando la apertura al comercio de uno o más puertos. La muestra de poderío naval y las noticias todavía recientes sobre las consecuencias nefastas de la "guerra del opio" en China (1839-1842) atemorizaron al régimen feudal

2 Literalmente significa "ciencia de lo japonés" y los escritos pertenecientes a tal denominación generalmente tienden a asumir que las gentes del Japón constituyen una sociedad cultural y socialmente homogénea, que los japoneses difieren drásticamente de toda otra civilización y, finalmente, implica cierto sentido de hostilidad contra todo aquello considerado ajeno a lo "auténticamente" japonés. Cf. P. Dale, The Myth of Japanese Uniqueness. San Francisco: St. Martins Press, 1986, p. i.

3 Dale (1986), p. 15. 
del shôgun Tokugawa y la tensa situación política derivó en la firma del tratado de Kanagawa el 31 de marzo del año siguiente, en virtud del cual Japón accedía a las peticiones de la administración de los Estados Unidos.

Los líderes japoneses no tardaron en darse cuenta de que, si deseaban evitar convertirse en otra de las colonias asiáticas, necesitaban modernizarse lo suficiente como para poder defender apropiadamente sus territorios de una posible agresión directa por parte de tropas extranjeras. En 1868, después de 230 años de aislamiento oficial, el sistema feudal fue finalmente abolido y el poder político devuelto al emperador. A partir de entonces la tecnología y la cultura Occidental fueron importadas con una premura vertiginosa iniciándose lo que se ha conocido desde entonces como la reforma Meiji. Sin embargo, junto a dicha apropiación, apoyada por el compromiso de traer grandes cantidades de expertos y profesores extranjeros ${ }^{4}$, los jóvenes japoneses más prometedores fueron también enviados al exterior a aprender el saber científico y artístico de Occidente. Su tarea principal fue la de adquirir conocimiento sobre las ideas y prácticas de los países más avanzados en materia tecnológica, comercial, militar e industrial, para luego regresar al Japón y supervisar la adopción de las costumbres extranjeras.

No obstante, en el campo de las humanidades, a pesar del dominio ideológico ejercido por el empirismo y el positivismo inglés de la época, fue la filosofía alemana la que encontró terreno fértil en Japón. Japón había empezado a sentir una identificación con Alemania, más que con cualquier otro país industrializado de aquel entonces, que le acompañaría fielmente hasta los desastrosos eventos de la Segunda Guerra Mundial.

Alemania había sido un país atrasado desde el punto de vista político o económico durante los siglos de expansión y colonización que trajeron riqueza y prosperidad a no pocos territorios europeos. Pero, durante el siglo XIX, después de haber sufrido en su propia piel la crisis y fractura de la cristiandad, con la dominación de poderes extranjeros y la transformación tardía y acelerada de una economía agraria a otra urbana e industrial, un movimiento de dolorosa autorreflexión surgió en este país. Los intelectuales alemanes se dieron a la búsqueda desesperada de unos valores y raíces culturales olvidados en el intrincado pasado de una sociedad cuya identidad se encontraba perdida entre tantos cambios profundos.

Tras haber caído bajo el hechizo del utilitarismo y el positivismo en los primeros años de la era Meiji (1868-1912), los japoneses tal vez también sin-

4 Tan sólo durante los diez primeros años de la era Meiji, unos 180 profesores extranjeros se encontraban enseñando en las recién fundadas universidades de Keiô Gijuku y Teikoku Daigaku. cf. J. González Valles, Historia de la filosofia japonesa. Madrid: Tecnos, 2000, p. 197. 
tieran la opresión de un vacío cultural como el ocurrido a los alemanes durante el mismo siglo. De forma similafr habían llegado rezagados al desarrollo industrial después de haber adoptado los valores del capitalismo. Ahora bien, en el caso específico del Japón, las viejas costumbres de vida desaparecieron aún más abruptamente y la importación masiva de ideas y usos se llevo a cabo durante un período de tiempo sumamente corto debido a las reformas introducidas en la era Meiji. Tal situación, junto con la errónea exaltación del desarrollo industrial, provocaron una reacción antagónica casi inmediata que disparó la búsqueda de los valores culturales originales del Japón. Tras el cuestionamiento de la negación superficial de todo lo japonés como obsoleto y la ciega adopción de todo lo Occidental como símbolo de progreso cultural, entre los intelectuales japoneses se dejaba sentir una gran necesidad de encontrarse a sí mismos de nuevo en las tradiciones autóctonas del pensamiento japonés.

Además, existía un problema adicional: el del trauma de un país que se había aislado del resto del mundo durante más de dos siglos para, luego, ser repentinamente forzado a despertar de un prolongado letargo cultural y tomar parte en la carrera mundial por la adopción de los valores técnicos y materiales de la industrialización. Todo ello les conduciría, quizá irremediablemente, a adoptar ideas occidentales que en sí mismas empezaban a colapsarse en su lugar de origen.

Karl Löwith, invitado por sus colegas japoneses a dar clases en la Universidad de Sendai después de los traumáticos eventos ocurridos en Alemania en 1933, escribió en 1940 un influyente ensayo titulado Der europäische Nihilismus [El nihilismo europeo]. En su epílogo, dedicado al lector japonés, reflexionaba sobre la conciencia inocente que había guiado las acciones tomadas durante la era Meiji:

"Cuando Japón entró en contacto con nosotros en la segunda mitad del siglo pasado y adoptó nuestros «progresos» con un admirable esfuerzo y una velocidad vertiginosa, nuestra cultura estaba en plena decadencia. En contraposición a los rusos del siglo XIX, sin embargo, los japoneses no se ocuparon críticamente de nosotros en aquel momento, sino que adoptaron al principio de forma ingenua y acrítica todo aquello que repugnaba a nuestras mejores mentes...Japón sólo nos conoció cuando era demasiado tarde, cuando nosotros ya no creíamos en nuestra propia civilización y lo mejor que teníamos era la autocrítica, de la que Japón, en cambio, no se enteraba"s.

5 K. Löwith, "Der europäische Nihilismus: Betrachtungen zur Vorgeschichte des europäischen Krieges" en Sämtliche Schriften. Stuttgart: Metzler, 1983, Vol. II. p. 533-4; trad. por A Kovacsics en El hombre en el centro de la historia: balance filosófico del siglo XX. Barcelona: Herder, 1998, p. 116. 
Nueve años después, Nishitani Keiji, uno de los pensadores japoneses más prominentes del siglo XX, reflexionaba sobre el escrito de Löwith y reconocía que la adopción indiscriminada de la cultura Occidental había hecho que los japoneses perdieran contacto consigo mismos porque no estaban interesados en la profundidad espiritual que los había definido en el pasado, sino sólo en trivialidades externas ${ }^{6}$.

Este encuentro entre Löwith y Nishitani es una muestra de cómo los profesores alemanes que visitaron las tierras japonesas jugaron un papel decisivo a la hora de estimular a los intelectuales de este país a investigar las causas de su situación histórica particular. Si los profesores incentivaban dicha búsqueda era porque, como en el caso de Alemania y Europa en general, todas las fuentes tradicionales de significado se habían colapsado o habían desaparecido debido al desarrollo desproporcionado de la tecnología y de la industria. Al mismo tiempo, la nueva fe depositada en la ciencia no bastaba para responder a las preguntas que les son propias a los seres humanos como tales, mientras que los temas humanísticos (relacionadas con lo que Wilhelm Dilthey llamó las "ciencias del espíritu" en contraste con las "ciencias de la naturaleza") habían sido relegados como irrelevantes. Concretamente en Japón, la industrialización de corte Occidental se había llevado a tal extremo que todo aquello que había definido al país, las propias artes inclusive, fueron disociadas de las ideas y prácticas ancestrales que habían sostenido e impulsado el desarrollo de la cultura durante todo su pasado (shintoismo, budismo y confucianismo).

El éxito de las políticas impulsadas por la reforma Meiji tiene repercusiones importantes incluso hoy en día, ya que, por ejemplo, la filosofía japonesa todavía está ausente de los planes de estudios universitarios. Sin embargo, este no fue siempre el caso, al menos no durante principios del siglo $\mathrm{XX}$.

\section{LLEGADA Y DESARROLLO DE LA FILOSOFIA ALEMANA}

La primera generación de intelectuales japoneses modernos fueron enviados a estudiar a Occidente casi inmediatamente después de la apertura, esto es, durante los años siguientes a 1860. Entre ellos, Tsuda Mamichi (1829-1903) y Nishi Amane (1826-1894), a pesar de que estudiaron sobre todo derecho y ciencias políticas, se encuentran entre los precursores del área de las Humanidades en Japón. Nishi, desde un principio más atraído hacia

6 Cf. K. Nishitani, The Self Overcoming of Nihilism, trad. por G. Parkes y S. Aihara. Albany: State University of New York Press, 1990,p. 176-178. Cf. también G. Parkes, "Ways of Japanese Thinking" en N. Hume (ed.), Japanese Aesthetics and Culture. Albany: State University of New York Press, 1995, p. 98-99. 
la filosofía que Tsuda, adoptó y acuñó los vocablos japoneses específicos (muchos de los cuales se encuentran en uso aún hoy en día) que traducían y hacían asequible gran parte de la terminología técnica de la filosofía Occidental $^{7}$. Nishi también fue pionero en el estudio de la estética ${ }^{8}$ e intentó, quizá prematuramente, aventurarse a interpretar las artes japonesas usando categorías inspiradas por el idealismo alemán. Estudió en Holanda y se sentía identificado con la filosofía política de Kant y con la posibilidad de alcanzar una "paz perpetua entre las naciones"; quizá fue el primero en hacer llegar a tierras niponas una copia de la Fenomenología del Espíritu de Hegel' Pero los estudios de estos dos importantes pioneros en el área de la estética estaban aún lejos de la profundidad de los trabajos que verían la luz con en las siguientes generaciones.

Casi seguidamente a estos estudios germinales, en los que por vez primera se intentaba integrar el pensamiento Oriental y el Occidental como una valiente travesía pero un poco a la deriva, fueron los profesores alemanes invitados por el gobierno Imperial los que tomaron las riendas de la instrucción y dirección de las clases en las universidades japonesas.

Entre los muchos extranjeros que vinieron durante la reorganización de la Universidad Imperial de Tokio después de 1886, hay dos que merecen especial atención dada su enorme influencia sobre los intelectuales japoneses que producirían los mejores y más creativos estudios en el campo de la estética japonesa. En primer lugar, Ernest F. Fenollosa (1853-1908), estadounidense de padre español y madre inglesa, quien estuvo en Japón desde 1878 hasta 1890 y regresó en múltiples ocasiones después de su primera estadía como profesor de filosofía y ciencias políticas. Fenollosa estudió estética en Harvard y su interés se centraba principalmente en el arte Oriental, lo cual lo impulsó a realizar largos e intensos viajes por China e India durante su estadía en Asia. Sus clases en Tokio versaron sobre estética y sobre las bases del pensamiento idealista alemán. Por otra parte, la labor educativa de Fenollosa fue de una gran envergadura, ya que fue mucho más allá de la de un humilde profesor de filosofía: en él es posible observar los primeros intentos de emprender un estudio en profundidad del arte japonés, de su ética y de sus características propias y definitorias.

Tras su estancia en Japón, Fenollosa se dedicó a escribir tratados sobre la ceremonia del té (The Book of Tea, 1906) y sobre el teatro Nổ (Accomplishment: a Study of the Classical Stage in Japan, 1916). Más allá del alcance

7 G. Piovesana, Contemporary Japanese Philosophical Thought. Nueva York: St. John's University Press, 1969, p. 11.

8 Cf. González Valles (2000), p. 208-210.

9 Cf. Piovesana (1969), p. 7 y p. 10. 
sustantivo y a largo plazo del calado intelectual de sus obras ${ }^{10}$, éstas sirvieron para despertar un interés renovado por las artes tradicionales de su país entre los intelectuales japoneses; en especial porque en aquel momento se encontraban en una situación de grave incertidumbre debido a la gran influencia de las artes y las ciencias occidentales junto a la renuncia voluntaria a sus valores culturales y a la riqueza de su propia tradición estética. El compromiso intelectual con Japón llevó a Fenollosa a involucrase también en la creación de la Escuela de Bellas Artes de Tokio y, debido a la gran trascendencia de su labor, le fue finalmente otorgada una condecoración gubernamental por el mismo Emperador Meiji.

Aunque Fenollosa ya se encontraba enseñando filosofía alemana, sobre todo la estética de Hegel, y un inglés de nombre Cooper se encontraba dando clases sobre los críticos de Kant, la filosofía alemana no empezó a ser estudiada rigurosamente en Japón hasta la llegada en 1887 de Ludwig Busse (1862-1907), especialista en Kant. Busse, junto a Raphael von Koeber (18481923) e Inoue Tetstujirô (1855-1944) -éste último formado en Alemania con los historicistas neokantianos Eduard Zeller y Kuno Fischer- formaron la generación de intelectuales alemanes profundamente influenciados por la filosofía alemana que se encargaría de educar a los filósofos japoneses más importantes de siglo $\mathrm{XX}^{11}$.

Antes de pasar a analizar más en detalle la influencia de la filosofía alemana en la estética japonesa, merece la pena detenerse en Raphael von Koeber. La figura de Koeber requiere especial consideración porque se encargó personalmente de tutorar al filósofo japonés de mayor prestigio en su país, Nishida Kitarô (1870-1945), así como a los pensadores más importantes del ámbito de la estética japonesa, entre ellos Ônishi Yoshinori (1888-1959) y Kuki Shuzô (1888-1941). Koeber se encontró en una posición extremadamente privilegiada pues, tras la partida de Fenollosa en 1890, se convirtió en la fuente teórica más influyente de la Universidad de Tokio, el lugar donde el estudio de la estética por parte de los intelectuales japoneses se inició con pleno ímpetu creativo.

$10 \mathrm{Al}$ parecer sus alumnos pensaban que era un profesor que tendía a ser más elocuente que profundo y sutil. $C f$. Y. Miyake, "The Introduction of Western Philosophy" en S. Ôkuma (ed.), Fifty Years of New Japan, Londres: Kraus, 1910, Vol. II, p. 231 y Piovenasa (1969), p. 26.

11 M. Yuso afirma: "Bajo el liderazgo de Inoue Tetsujirô la filosofía alemana empezó a disminuir la posición dominante de la filosofía de origen inglés. Inoue recordaba: ' ....Mis colegas y yo fuimos los verdaderos responsables que hicieron de la filosofía alemana la tendencia filosófica dominante en el ambiente académico japonés' " en su obra Zen and Philosophy: an Intellectual Biography of Nishida Kitarô. Honolulu: University of Hawai'i Press, 2002, p. 31-32. 


\section{Filosofía ALemana, estética jaPonesa}

Koeber llegó a Tokio en 1893 por recomendación de Eduard von Hartmann y aunque su contrato era sólo por tres años, se quedó inicialmente durante veintiuno. El preludio de la Primera Guerra Mundial le impidió regresar a Alemania tras su prolongada estadía en tierras extranjeras, así que, decidió finalmente quedarse enseñando historia y filosofía en Japón hasta su fallecimiento en 1923. Entre los estudiantes de la Universidad Imperial de Tokio, Koeber dejó una impresión no igualada por ningún otro profesor extranjero antes que él. Quizá dicha atracción radicaba en su presencia, refinamiento y erudición artística y filosófica, rasgos que lo acercaban al ideal del sabio de la escuela de Confucio. En efecto, Koeber no sólo era una persona que poseía un extenso conocimiento teórico de las artes sino que además era un artista de gran nivel, ya que había tenido el gran honor de haber estudiado música en el Conservatorio de Moscú bajo la tutela de Tchaikovsky en $1879^{12}$. La mejor prueba de sus cualidades como modelo ejemplar de sabio (o sensei como era llamado en el ambiente académico a pesar de su estatus como extranjero) fue que sus estudiantes se convirtieron en los más destacados representantes de la Escuela de Kioto ${ }^{13}$. Casi todos ellos sintieron el compromiso de escribir algún ensayo en su honor recordando el papel y la profunda influencia que había ejercido sobre sus respectivos caminos filosóficos. Entre ellos se encuentran Natsume Sôseki (1867-1916) (uno de los escritores más ilustres del Japón), Watsuji Tetsurô (1889-1960), Ônishi Yoshinori, Kuki Shuzô y Nishida Kitarô. En especial éste último estuvo presente en las clases de Koeber desde su llegada a Tokio y consideró apropiado extender el alcance de su influencia a "todo intelectual que posea un estilo académico impresionante y contribuya al mundo académico japonés" 14 .

Koeber jugó un papel significativo en la implantación de los estudios del pensamiento griego y medieval en Japón; y aunque en el área de la estética su preferencia personal fue claramente Arthur Schopenhauer, fue gracias a

12 Piovenasa (1969), p. 50.

13 James W. Heisig ha compuesto recientemente uno de los pocos textos disponibles en castellano donde se puede encontrar un análisis detallado sobre algunas de las figuras más relevantes de la Escuela de Kioto. Cf. Filosofos de la nada: un ensayo sobre la Escuela de Kioto. Barcelona: Herder, 2002. Por otro lado, Agustín Jacinto Zavala ha preparado y traducido dos antologías de textos originales, las cuales incluyen una gran variedad de exponentes de la "Escuela" y de otros colegas allegados a ella. Cf. Textos de la Filosofia Japonesa Moderna. Zamora: Colegio de Michoacán, 1995, Vol. I y La otra filosofía japonesa. Zamora: Colegio de Michoacán, 1997. Vol. II.

14 M. Yusa (2002), p. 40. 
Koeber que Hegel, los neokantianos y en menor medida Schiller, Schelling y Nietzsche ${ }^{15}$ se convertirían en los autores alemanes que mayor peso tendrían en los estudios de estética japonesa más notables de principios del siglo XX.

Pero Koeber no era simplemente un profesor de una historia que pertenecía al pasado abstracto de un continente lejano y ajeno; su más importante aportación se basó en haberle conferido una orientación propiamente filosófica a las incipientes investigaciones de sus discípulos. Koeber puso mucho énfasis en el desarrollo personal de sus estudiantes y en estimular la búsqueda interior de una nueva comprensión de la vida en el reino del arte. Además, a través de sus enseñanzas sobre el idealismo alemán y las estrategias hermenéuticas del humanismo del siglo XIX de filósofos como Wilhelm Dilthey, preparó el soporte intelectual para el kyôyôshugi (la traducción de la palabra alemana Bildung). Kyôyôshugi fue un movimiento de gran importancia particularmente para los estudios de estética durante la era Taishô (1912-1926) debido a que consideraba las bellas artes como la esencia misma de la cultura. Sin duda alguna "Koeber sembró las semillas del Humanismo en Japón"16 e hizo que el mundo académico japonés sustituyera una concepción abstracta del hombre por otra más concreta, dirigida a desarrollar la capacidad de comprender las circunstancias sociales específicas apropiándose el conocimiento del pasado.

Como se ha visto, el papel de los profesores y los filósofos alemanes fue clave para el desarrollo de los estudios de estética en Japón. Por un lado, sirvió al propósito de redescubrir el espíritu japonés y de edificar "cultura"

15 La recepción del pensamiento de Nietzsche en Japón durante esta época fue casi sin excepción extremadamente hostil y, en algunas raras ocasiones, ambivalente. Koeber consideraba que "sus enseñanzas tenían que ser fuertemente rechazadas como una muestra de la más extrema forma de egoísmo" y su opinión, claramente, creó el tono interpretativo con el que generalmente fue entendido. El rechazo llego a tales extremos que las autoridades gubernamentales expulsaron de sus cargos a aquellos profesores que se atrevían a defender, aún de manera muy indirecta, la perspectiva de Nietzsche. Tobari Chikufu y Nakajima Tokuzô fueron algunos de los profesores que se encontraron siendo víctimas de dicha represión, ya que el gobierno consideró que sus clases animaban a seguir las enseñanzas de Nietzsche, es decir, fomentaban a los estudiantes a que apreciaran la vida y doctrina de un psicópata solitario y, por tanto, defendían un modo de vida incompatible con el sistema Imperial y las costumbres tradicionales japonesa.. $C f$. G. Parkes "The early reception of Nietzsche's philosophy in Japan" en Nietzsche and Asian Thought. Chicago y Londres: University of Chicago Press, 1996, y H. Becker, Die friihe Nietzsche-Rezeption in Japan (1893-1903): ein Betrag zur Individualismusproblematik im Modernisierungsprozess. Wiesbaden: Harrassowitz, 1983.

16 M. Sakabe, "Kuki Shuzô no sekai" en Fuzai no uta. Tokio: TBS Buritanika, 1990, p. 191-192, citado por L. Pincus, Authenticating Culture in Imperial Japan: Kuki Shuzo and the rise of National Aesthetics. Berkeley y Londres: University of California Press, 1996, p. 34. 
como el verdadero sustento de la profunda espiritualidad de una nación y, por el otro, proporcionó una salida a la noción de "civilización" entendida sólo como "mecanización" y "progreso". De acuerdo con lo que nos indica uno de los testimonios de la época "al considerar los efectos producidos por la recién importada filosofía idealista de Alemania, podemos darnos cuenta de que armonizó con el idealismo tradicional del Japón, fomentando, por un lado, la creación de un espíritu nacional particular y, por otro, la estimulación de un pensamiento oriundo" 17 .

No obstante, antes de abordar la influencia de estos autores sobre la filosofía del arte en Japón, hemos de preguntarnos por qué Kant, figura clave de la estética cuyo pensamiento, como se vio anteriormente, fue enseñado sin interrupción en las universidades desde los principios de la era Meiji, sin embargo, no forma parte del grupo de filósofos fundamentales en el desarrollo de la estética japonesa.

\section{LA ESTÉtica dE KANT EN JAPÓN Y LA SOMBRA DE SCHOPENHAUER}

La filosofía de Kant fue dada a conocer en Japón con la llegada de los primeros profesores extranjeros a finales del siglo XIX. Aunque las tres Críticas estaban siendo estudiadas bajo la tutela de profesores como Busse, en el caso específico de la filosofía del arte, la primera traducción al japonés de algunas secciones de la Crítica de la Facultad de Juzgar fue hecha por Fukada Yasukazu (1878-1928) y distribuida en el ambiente académico durante los años posteriores a 1900. Dicha traducción parcial probablemente fue realizada originalmente con la intención de hacer que uno de los textos claves de la historia de la filosofía del arte fuera más asequible para unos lectores que, de por sí, se enfrentaban a la gran dificultad de tener que aprender alemán e inglés tan sólo para poder asistir a las clases en la Universidad.

La influencia de las enseñanzas de Koeber sobre los intereses filosóficos de los intelectuales japoneses que tuvieron contacto con él quedan claramente ejemplificada en el caso de Fukada. Éste fue considerado su estudiante favorito debido, en parte, a que tenía una prodigiosa habilidad para el aprendizaje de lenguas extranjeras y gracias a ello fue invitado a quedarse en su hogar durante cinco años (desde 1902 a 1907). Fukada "tenía un dominio prọfundo de la estética de Kant (...) no obstante, con respecto a su inclinación hacia el monismo en la belleza artística, Fukada prefería a Hegel, como el mismo admitía"18.

17 U. Kaneko, Western Influences in Modern Japan: A Survey of Philosophy in Japan 1870-1929. Tokio: Institute of Pacific Relations, 1929, p. 7.

$18 \mathrm{~K}$. Yoshioka, "The thought and times of Fukada Yasukazu" en M. Marra (ed.), A History of Modern Japanese Aesthetics. Honolulu: University of Hawai'i Press, 2001, p. 253. 
La desilusión de Fukada con respecto al pensamiento kantiano muestra cómo éste no jugó un papel prominente durante los inicios del estudio de la estética en Japón. En el caso concreto de Fukada, este hecho puede ser parcialmente explicado por la mencionada influencia de las preferencias filosóficas de Koeber: Schopenhauer, -como es sabido, un crítico severo de Kant-, y los estudios de Eduard von Hartmann ${ }^{19}$, cuyo libro titulado Aesthetik fue publicado en dos partes en 1886-7 (traducidos al japonés en 1899) y había sido considerablemente influenciado por Hegel.

Pero, dejando a un lado el innegable peso teórico de Koeber, existen ciertos elementos constitutivos de la estética kantiana que eran por sí mismos discordantes y en muchos casos directamente incompatibles con los principios de la estética japonesa, a pesar de que el autor era ampliamente conocido dentro del ambiente universitario. Dichas divergencias teóricas no se encontraban limitadas a los posibles conflictos inherentes al propio pensamiento de Kant, los cuales fueron tratados por autores como Ônishi Yoshinori ${ }^{20}$ (éste en 1931 publicó su Estudio sobre la Crítica de la Facultad de Juzgar de Kant en donde trató de "explicar el camino lógico que llevó a Kant al fallo interno de la estructura de la Tercera Crítica, pero especialmente en la estética") ${ }^{21}$.

Uno de los problemas principales residía en la separación que Kant estableció entre las bellas artes y los oficios artesanos. Las primeras eran las únicas realmente libres, mientras que el trabajo manual implicado en la artesanía era solamente parte de "un empleo que de por sí es un trabajo desagradable, fatigoso y es sólo atractivo a través de su resultado, por ejemplo, la paga"22 (CJß43). Teniendo en cuenta que algunas de las artes más apreciadas y respetadas en Japón, como la cerámica (de la cual se deriva una de las producciones más emblemáticas del arte japonés: las delicadas tazas de té) o la forja de espadas (katanas), hubieran sido consideradas por Kant como "artesanías, se comprende el poco atractivo que pudiese despertar este autor como líder de la fundación teórica de la estética japonesa. Además, estas "artesanías" están íntimamente ligadas a dos de los principios definitorios de la estética japonesa, a saber, wabi y sabi, los cuales no podrían haber sido excluidos de un estudio meticuloso del Japón sin dejar un vacío teórico considerable.

19 Antes de su llegada a Japón, Koeber había publicado un estudio sobre la filosofía de Hartmann bajo el título de Das philosophische System Eduard von Hartmann's. Breslau: Koebner, 1884 y dos libros sobre Schopenhauer: Schopenhauer's Erlösungslehre. Berlín: Duncker, 1881 y Die Philosophie Arthur Schopenhauers. Heidelberg: Weiss ,1888.

20 In 1932 Ônishi terminó la primera traducción íntegra de la Critica de la Facultad de Juzgar, publicada por Iwanani Shoten.

21 M. Yamamoto, "The aesthetic thought of Ônishi Yoshinori" en M. Marra (2001), p. 167.

22 I. Kant, Kritik der Urteilskraft (CJ) en Sämtliche Werke. Vol. V, ed. por G. Hartenstein, Leipzig: Leopold Voss, 1867. 
Solamente para dar una idea de lo fundamentales que son estos dos términos, nos acercaremos brevemente a los estudios realizados por uno de los más importantes intelectuales japoneses en el área de la estética zen y amigo de Nishida desde su juventud: Daisetz T. Suzuki (1870-1966). Suzuki, en su texto clave sobre la estética japonesa, El Zen y la Cultura Japonesa, describe wabi como "pobreza", "el ser pobre significa no encontrarse dependiendo de las cosas del mundo y, sin embargo, sentir interiormente la presencia de algo que posee un valor muy alto"23. Wabi también implica aquello que es simple y común más allá de la artificialidad y cuando contiene también sabi, llega a ser la expresión de un estado natural alcanzado mediante una intención creativa no forzada ${ }^{24}$. Sabi complementa a wabi al permitir la apreciación de la dureza, imperfección y simplicidad no afectada de lo rustico. "Sabi consiste en lo rústico sin pretensión o la imperfección arcaica, la simplicidad aparente o la ejecución sin esfuerzo y la riqueza de las asociaciones históricas" 25 . Teniendo en cuenta la totalidad de las "artesanías" japonesas es posible que todas estas características se encuentren mejor representadas en los utensilios de la ceremonia del té -una de las artes más importantes del Japón-y en la arquitectura de las estancias destinadas para dichas ceremonias.

Suzuki también le dedica una sección importante de su ensayo a lo que él llama "el amor japonés a la naturaleza" ${ }^{26}$.En este caso específico, "amor" significa no una simple apreciación pasiva de la naturaleza sino una armonización con los elementos que la definen. Cuando se construyen los templos o las habitaciones para el té "nunca se convierten en intrusos del ambiente, sino que pertenecen al esquema general del lugar"27. Esta faceta estética representa, por lo menos, dos aspectos de las enseñanzas del budismo zen, esto es, pone el énfasis en la "ausencia del ego y en la unión del sujeto con el objeto en la nada (sûnyatâ)" $28 ; \mathrm{y}$, asimismo, hace explícito el sentido de interdependencia existente entre todos los seres vivientes y, por tanto, pone de relieve la importancia de las múltiples relaciones que definen nuestras vidas. Es por ello por lo que para Suzuki el "amor a la naturaleza" va más allá de una inocente y pasiva conexión con el medio ambiente, al contrario de lo sugerido por escritores como Fernando García Gutiérrez ${ }^{29}$, quienes, al desvincular lo humano de sí mismo,

23 D.T. Suzuki, Zen and Japanese Culture. Princeton: Princeton University Press, 1993, p. 23.

24 S. Hisamatsu, Zen and the Fine Arts. Tokio: Kodansha International, 1971, p. 32.

25 Suzuki (1993), p. 24.

26 Cf. Suzuki (1993), p. 329-397.

27 Suzuki (1993), p. 336.

28 Suzuki (1993), p. 352.

29 Cf. F. García Gutiérrez, Japón y Occidente: influencias reciprocas en el arte. Sevilla: Ediciones Guadalquivir, 1990 y El zen y el arte japonés. Sevilla: Ediciones Guadalquivir, 1998. 
lo sitúan lejos de una apreciación del amor que se sustenta en los preceptos sociales del budismo y del confucianismo antiguo. Defender tal tesis significaría dejar de lado algunos de los aspectos definitorios del trasfondo filosófico de la sociedad japonesa.

Ahora bien, si se comparan aquellos aspectos que Suzuki considera determinantes en la estética japonesa con la noción kantiana de lo bello en la naturaleza, es posible observar otra discrepancia más entre los intereses de los autores japoneses y el pensador alemán: en principio, uno puede verse tentado a encontrar apresuradamente similitudes aparentes cuando Kant expone que la obra de arte debe parecerse a un producto de la naturaleza $(\mathrm{CJ} \S 45)$ puesto que la belleza de la naturaleza siempre sobrepasa a aquella perteneciente al arte. Pero la belleza que Kant encuentra en la naturaleza es mediada por el juicio estético, el cual en sí mismo no se relaciona con el objeto en tanto que existente; la belleza se alza como un tipo de placer desinteresado respecto de la existencia del objeto ${ }^{30}(\mathrm{CJ} \$ 5)$ y, por tanto, es una expresión de placer que coloca mayor importancia en lo subjetivo (CJ§1 y $\$ 49)$, a pesar de que Kant defiende que "lo bello es aquello que, sin ningún concepto, genera placer universalmente" (CJß9).

La noción de lo sublime en Kant puede ayudarnos a iluminar aún más la contraposición entre su estética y la japonesa. Lo sublime tiene en común con lo bello que "ambos generan placer en sí mismos" (CJ\$23). Lo sublime no es propiamente un objeto de los sentidos (CJ\$25) sino que apunta hacia la existencia de una facultad del pensamiento que transciende la experiencia (CJ\$26). En el caso de lo sublime kantiano, la naturaleza es experiencia en tanto es fuente de temor (CJ\$28) y no será tal a menos que nuestra inferioridad se convierta en un estado de independencia y superioridad sobre ella. Kant mismo explica cómo "lo irresistible de la naturaleza nos fuerza, por un lado, a reconocer nuestro desamparo, pero, por el otro, revela una facultad que nos permite estimarnos a nosotros mismos como independientes de ella (...) la humanidad se mantiene sin humillación dentro de nuestra persona" (CJß28). Esta noción de la independencia de lo humano sobre lo natural, plenamente ilustrada, se encuentra, sin embargo, en oposición clara a la interpretación de Suzuki de la estética japonesa. La armonía entre lo humano y su ambiente y la ausencia de intromisión por parte del hombre en la naturaleza son características esenciales de la estética japonesa que están por completo ausentes en la concepción kantiana de lo sublime.

30 Con respecto al desinterés estético en Kant, Steve Odin en su Artistic Detachment in Japan and the West: Psychic Distance in Comparative Aesthetics. Honolulu: University of Hawai'i Press, 2001, ha tratado de compararlo, de manera acontextual, con la noción budista del no apego presente en gran parte de la literatura japonesa. 
Ônishi Yoshinori fue uno de los autores que reconocieron explícitamente tales diferencias entre la estética japonesa y la kantiana. En su Estética (Bigaku), completada en 1957 pero publicada póstumamente en 1959, se planteó la posibilidad de enarbolar nuevas definiciones filosóficas a partir de las comparaciones entre el pensamiento occidental y el oriental. Pero cuando Ônishi intentó comparar yûgen, otra de las características definitorias de las artes en Japón, con la concepción kantiana de lo sublime, se encontró con diferencias irreconciliables entre ambos términos. Yâgen, comúnmente definido como expresión de una profunda sutileza u oscuridad presente en la elusiva apertura artística de la infinitud que comprende todos los seres ${ }^{31}$, conducía a una relación entre el artista y la naturaleza que difería completamente de Kant. Makoto Ueda explica en su ensayo sobre Ônishi que "mientras el filósofo alemán recalcaba la resistencia de la razón humana en oposición a la fuerza sobrecogedora de la naturaleza, Ônishi desea enfatizar el amor y la armonía del hombre con la naturaleza. Él cree que la belleza sublime acaece cuando el artista se aproxima a la naturaleza, no como a un enemigo a conquistar, sino como a un objeto de contemplación estética"32.

Todavía podemos señalar otra divergencia notable entre la estética de Kant, tal y como es presentada en la tercera Crítica, y los intereses de los intelectuales japoneses en relación con el mencionado proyecto humanístico de indagar sus fundamentos filosóficos autóctonos. Si, tal y como se afirma en la Crítica de la Facultad de Juzgar, los juicios estéticos no revelan ningún tipo de conocimiento, ¿cómo podría Kant servir de adalid en la tarea de investigar la identidad del espíritu y la cultura japonesa en el reino de las artes?

Kant inaugura la Crítica diciendo que "para poder discernir si algo es bello o no, no remitiremos nuestra representación del objeto al entendimiento para obtener conocimiento, sino que la relacionaremos por medio de la imaginación (...) el juicio del gusto no es un juicio de conocimiento, por lo tanto, tampoco lógico, sino estético, lo cual significa que su fundamento determinante no puede ser sino subjetivo" (CJ§1). Más aún, Kant afirma que el juicio estético simplemente se ocupa de representaciones $y$, aunque es una facultad que tiene la capacidad de distinción, se encuentra totalmente separada y "no añade nada al conocimiento" (CJ§1). Quizá debido a que Kant quería rechazar por completo la estética de corte racional de Alexander Baumgarten, quien consideraba los juicios estéticos como formas de conocimiento, le negó a la obra de arte la po-

31 S. Hisamatsu (1971), p. 33.

32 M. Ueda, "Yûgen and Erhabene: Ônishi Yoshinori's attempt to synthesize Japanese and Western aesthetics" en J.T. Rimer(ed.), Culture and Identity: Japanese Intellectuals During the Interwar Years. Princeton: Princeton University Press, 1990, p. 293. 
sibilidad de proporcionar cualquier tipo de conocimiento ya que en todo caso el juicio procede del ambiente íntimo del sujeto. Esto es, por cierto, el fundamento de la crítica de la estética kantiana por parte de Gadamer en Verdad y Método, quien la caracterizó sin más como "un sentimiento subjetivo a priori de la vida". Gadamer (así como los filósofos japoneses) continuó el legado crítico de Hegel, cuando se sintió consternado porque Kant creaba unos "fundamentos autónomos de la estética, libres de conceptos, y no se preocupaba por las preguntas relacionadas con la verdad en el dominio del arte" 33 .

Aunque Kant reconoció el valor del juicio estético y le otorgó su propio dominio, sin embargo, dejó claro que no estaba relacionado con el campo de lo racional y su conocimiento. Desde estas premisas, quedaba cerrada la posibilidad de que el arte pudiera manifestar aspectos reconocibles de la cultura a la cual pertenecía.

Al parecer, los autores japoneses compartían unos sentimientos críticos respecto a Kant muy parecidos a los descritos anteriormente, ya que, ninguna de las obras representativas de la estética japonesa siguió los pasos del proyecto kantiano de inquirir sobre la bases subjetivas de los juicios estéticos. Entre éstas cabe destacar el estudio realizado por Kuki sobre el submundo japonés durante la era Edo titulado La Estructura de lo Iki $(1930)^{34}$, el muy vendido Peregrinaje a los Templos Antiguos (1919) de Watsuji el cual generó toda una moda de interés estético por los lugares más antiguos del Japón y fue complementado por su Estudio sobre la Historia del Espíritu Japonés (1940), el refinado Zen y la Cultura Japonesa (1938) de Suzuki, Zen y las Bellas Artes (1958) un extraordinario estudio realizado por Hisamatsu, discípulo de Nishida en la Universidad de Kioto y, finalmente, quizá el trabajo que ejerció mayor influencia en este campo, Yûgen y Aware (1939) de Ônishi.

$\mathrm{Y}$ aunque los escritos dedicados a las formas de la conciencia estética no fueron olvidados del todo ${ }^{35}$, nunca gozaron de una gran popularidad ni ejercieron gran influencia en los estudios de estética en Japón. Por el contrario, en las obras mencionadas anteriormente es posible observar un proyecto en sí distinto, a saber, un intento de encontrar una voz filosófica original basada en una combinación entre los principios filosóficos inherentes a las obras de arte mismas y las ideas que procuraron su existencia y su historia. En otras palabras, los intelectuales japoneses se encontraron utilizando las artes como un sendero para conseguir el conocimiento que los definía como cultura.

33 H.G. Gadamer, Wahrheit und Methode. Tubinga: Mohr, 1965, p. 56.

34 Existe una traducción parcial de la obra en castellano en J. Zavala (1997).

35 Un ejemplo de tales trabajos fue realizado por Nishida en su Arte y moralidad (1923) pero, tal y como hizo con la mayoría de los aspectos de su filosofía, cambió de parecer en sus años de madurez y escribió entonces un ensayo profundamente influenciado por Hegel bajo el título de La creación artística como un acto de fundamentación histórica (1941). 
Arthur Schopenhauer es otro pensador a tener en cuenta, tanto para justificar la mencionada escasa aceptación de Kant-recordemos que lo consideraba una persona que muy posiblemente nunca tuvo la ocasión de observar una obra de arte de alguna importancia ${ }^{36}$, , como por su propia contribución personal a la estética japonesa gracias a su teoría de la liberación a través del arte. Ésta teoría, por cierto, también atrajo cierto interés a principios del siglo XX en relación con la crítica de Nietzsche a la sociedad occidental y su pretensión de poder superar el desgarramiento de ésta mediante la creación de nuevos individuos ${ }^{37}$.

Por tanto, lo que los autores japoneses encontraron atrayente en la estética de Schopenhauer era que la teoría del pensador alemán de la liberación a través del arte era considerada por ellos como una salida al problema del nihilismo que, como hemos visto, sentían que habían heredado del Occidente. Pero, por otro lado, el interés que Schopenhauer demostró por la filosofía india y el budismo antiguo, puede que también lo haya ayudado a ser un autor más fácilmente asimilable en Japón. Su concepción del mundo como mera representación y la habilidad del arte para calmar las fuerzas y los impulsos de la voluntad no eran concepciones de por sí lejanas a la sensibilidad budista japonesa.

Pero más allá de su idiosincrasia, de sus escritos erráticos, de su autodeclaración como el verdadero heredero de Kant y de su gran sentimiento de superioridad sobre Hegel, lo que importa señalar es que Schopenhauer ofrecía la posibilidad de sobreponerse a los orígenes del sufrimiento humano (MVR, 264) mediante la obtención, no sólo de un mero conocimiento a través del arte (MVR, 273), sino de un conocimiento de un orden que sobrepasaba las experiencias comunes y aún las teorías científicas. El arte se había convertido, así, en una fuente de redención y un nexo con la totalidad del mundo. Sin embargo, la constatación de lo efímero prevalece en su filosofía y al final, su noción de la experiencia estética sólo es capaz de revelar la naturaleza perecedera de todas las apariencias y nunca va más allá de reconocer la triste

36 Cf. A. Schopenhauer, Die Welt as Wille und Vorstellung (MVR). Stuttgart: Reclam, 1987, apéndice.

37 La otra alternativa filosófica que ofrecía una crítica profunda sobre las consecuencias de la industrialización y la explotación era, naturalmente, Karl Marx. Los libros de Marx fueron dados a conocer en Japón por Kozaki Hiromichi en 1881, cuando aún Marx y Engels estaban vivos, y el primer partido socialista asiático fue organizado en Japón tan sólo un año después en 1882. Pero, a pesar de la prolongada historia del pensamiento crítico socialista japonés, por razones obvias, las ideas revolucionarias de Marx nunca resultaron compatibles con los intereses del gobierno Imperial y fueron suprimidas brutalmente en numerosas ocasiones. $C f$. Piovesana (1969), p. 52. 
condición de la existencia humana y el necesario alejamiento y renunciación a ella ${ }^{38}$.

Schopenhauer había mostrado la posibilidad de superar la desesperada existencia en el océano del nihilismo mediante la acción liberadora del arte y la naturaleza superior del conocimiento generado por ella, pero, sin embargo, su pensamiento no ofrecía una salida exhaustiva del nihilismo más allá de la pura y vacía negatividad. Existía, pues, una clara necesidad de otras fuentes filosóficas para completar el proyecto humanista, de manera tal que combinase productivamente la experiencia liberadora y la búsqueda interna de los valores culturales que se habían perdido durante la adopción de las ideas extranjeras en el período Meiji. El vacío teórico había sido llenado, como se mencionó anteriormente, por dos ramas de la filosofía historicista: Fenollosa, por un lado, dando a conocer a Hegel y, por el otro, los neokantianos. Éstos ejercieron su influencia por dos vías: por una parte, a través de la introducción de su pensamiento en Japón gracias a Koeber, como se ha mencionado, y, por otra, a través de la formación que recibieron los pensadores japoneses que viajaron a Alemania durante los años veinte principalmente.

\section{Hegel y los Neokantianos}

Dado el notable éxito de las clases de Fenollosa en el ambiente universitario, en los círculos de artistas y en la reflexión filosófica japonesa en general, sería equivocado pensar, como algunos escritores han hecho, que éste sólo fue capaz de exponer una "versión reduccionista del gran sistema hegeliano" ${ }^{39}$. Más bien habría que decir que Fenollosa contribuyó en los inicios de la estética en Japón proporcionando las bases para una aproximación hermenéutica basada en la estética de Hegel. Sólo entonces sería posible emprender rigurosamente el proyecto hegeliano (y no simplemente invertirlo) ${ }^{40}$.Ello conllevaba ampliar el alcance de las indagaciones originales de Hegel hasta abarcar las tradiciones asiáticas más allá de las limitadas y desfavorables condiciones intelectuales del siglo XIX.

No obstante, Hegel mismo, en sus Lecciones de Filosofía de la Historia (1830), había proporcionado los principios filosóficos para que dicho proyecto se iniciase: era necesario que las gentes del mundo, o en este caso de Japón,

38 Cf. A. Schopenhauer, Aphorismen zur Lebensweisheit. Munich: Goldmann, 1978, p. 159.

39 J.T. Rimer, "Hegel in Tokyo: Ernest Fenollosa and his 1882 lecture on the truth of art" en M. Marra, Japanese Hermeneutics: Current Debates on Aesthetics and Interpretation. Honolulu: University of Hawai'i Press, 2002, p. 105.

40 Cf. M. Marra, Modern Japanese Aesthetics: a reader. Honolulu: University of Hawai'i Press, 1999, p. 65. 
buscaran "el punto más alto de su desarrollo, a saber, alcanzar la concepción filosófica de su vida y de su condición"41(XII, §88). Por tanto, al reflexionar sobre las artes japonesas, los intelectuales estaban, en términos hegelianos, "colocándose a sí mismos como objeto de su propia contemplación: pero tal reflexión no puede desarrollarse por sí misma objetivamente en su esencia natural excepto pensándose a si misma."(XII, $\$ 88$ las cursivas son mías). Esto significaba la apropiación de la filosofía de Hegel tal y como Fenollosa y Koeber habían deseado, a saber, sirviendo como base para la búsqueda de la:

"Historia de un principio [en este caso japonés] característico del espíritu -el genio peculiar de una nación. Es dentro de las limitaciones de estas características que el espíritu de una nación manifestado concretamente expresa todos los aspectos de su conciencia y voluntad. Todo el ciclo de su compresión: su religión, su política, su ética, su legislación e incluso sus ciencias, sus artes y su tecnología, todas llevan su sello."(XII, §72).

La búsqueda de tales principios en las artes, las cuales portan el "sello" y las características del espíritu japonés, fue claramente la tarea emprendida por los autores japoneses que siguieron de cerca las enseñanzas de Fenollosa y Koeber ${ }^{42}$. Fenollosa había intentado iniciar dicho proyecto por sí mismo al investigar los valores y las características definitorias de la cultura japonesa en las artes; no obstante, fue Okakura Kakuzô (1862-1913) quien, después de trabajar muy de cerca con Fenollosa, heredó su puesto en la Escuela de Bellas Artes de Tokio y continuó su deseo de sensibilizar a los japoneses acerca de los valores inherentes de sus artes autóctonas. Okakura, siguiendo de cerca a Hegel, consideraba "el arte estaba profundamente enraizado en la historia, como todo otro fenómeno social, y que no era como algo que de

41 G.W.F. Hegel, Werke, ed. por E. Moldenhauer y K. M. Michel, Frankfurt del Main: Suhrkamp, 1969-1971. El primer número hace referencia al tomo y el segundo al parágrafo o a la página según se indica.

42 Nishida, quien, como se vio, fue un aplicado estudiante de Koeber, dio una serie de conferencias abiertas al público en general en la Universidad de Kioto en 1938, en las cuales expuso un modelo claro de cómo el proyecto "hegeliano" fue incorporado en su filosofía y de cómo éste debía alentar a otros a perseguir los mismos fines de explicar la cultura japonesa mediante el análisis de su historia, instituciones y civilización. Más aún, si Japón aspiraba a ser reconocido como una cultura viviente que jugaba un papel relevante en los asuntos globales era porque, para Nishida, su país era capaz de verse a sí mismo determinado por sus tradiciones y, al mismo tiempo, capaz de contribuir significativamente en la configuración de una cultura global. $C f$. $\mathrm{K}$. Nishida, "The problem of Japanese culture" en R. Tsunoda, T. de Bary y D. Keene (ed.), Sources of Japanese Tradition. Nueva York: Columbia University Press, 1958, Vol. II, p. 350-365. 
pronto brota de la nada, como la planta mitológica udumbara, la cual florece una vez cada tres mil años" ${ }^{\prime 3}$. Pero, Okakura pretendía (quizá con excesiva ambición) inclusive superar las investigaciones sobre la estética llevadas a cabo hasta entonces, ya que deseaba encontrar en las artes de toda Asia, y no sólo en Japón, la manifestación de las ideas filosóficas que definen el espíritu asiático como un todo ${ }^{44}$.

Las consideraciones de Okakura nos ofrecen un ejemplo específico de cómo las investigaciones sobre la estética japonesa estaban asentadas firmemente en la filosofía del arte de Hegel, en la cual las obras de arte son consideradas en sí una vía por la cual el espíritu se manifiesta como verdad mediante el uso de lo sensual (XIII,127). Acaso ésta sea también una muestra del alcance de la yuxtaposición entre la liberación a través del arte propuesta por Schopenhauer y la filosofía hegeliana. Ambas pudieron ser combinadas de manera tal que resultó atractiva para los japoneses porque, en primer lugar, para Hegel el arte también genera "conciencia y expresa los más profundos intereses del hombre, esto es, la verdad más comprensiva del espíritu" (XIII,21). En segundo lugar, es así como la autorreflexión requerida para escapar a la trampa nihilista y devolverle sentido a las gentes obtenía un objeto, a saber: el arte. El arte podía ser estudiado a través de la historia japonesa de modo que "el contenido de ésta se encontraba conectado con el curso de las formas artísticas a través de las cuales el espíritu, considerado como manifestación artística, produce conciencia de sí mismo"(XIII,103).

A este trasfondo hegeliano habría que añadir otra influencia más que, en cierto modo, también se deriva del propio pensamiento hegeliano: la filosofía historicista neokantiana. Como ya se ha dicho, a pesar de que Koeber difundió la filosofía neokantiana y de que sus estudiantes ampliaron dicha formación yendo a Alemania, la influencia de esta rama del pensamiento sobre las obras de filosofía en Japón es comúnmente subestimada. Los continuos peregrinajes de jóvenes japoneses a Heildelberg y Friburgo ("Escuela de Baden") nos muestran cómo éstos no se sentían atraídos hacia la otra escuela neokantiana de Marburgo, la cual tendía a ser más consecuente y estricta con el proyecto kantiano de investigar los fundamentos, métodos y límites del conocimiento de las ciencias naturales. Esta elección resulta aún más significativa si tenemos en cuenta que los que estaban en Marburgo, si lo hubieşen deseado, podían haber estado en contacto directo con los miembros más representativos de la escuela de dicha ciudad mientras estudiaban junto al entonces joven discípulo

43 K. Okakura, "Lecture to the Painting Appreciation Society" en M. Marra (1999), p. 75.

44 K. Karatani, "Japan as Art Museum: Okakura Tenshin and Fenollosa" en M. Marra (2001), p. 49. 
de Husserl: Martin Heidegger ${ }^{45}$. Los miembros de la "Escuela de Baden", como Wilhelm Windelband y su discípulo Heinrich Rickert, se centraban en el legado de Wilhelm Dilthey y el interés de éste por la relación entre la historia, la cultura y las humanidades. Para los japoneses, que no habían encontrado ninguna fuente relevante de significado para su cultura en las ciencias importadas de Occidente, la opción era evidente.

Abe Jirô (1883-1959), quien ayudó a dar a conocer a Nietzsche en Japón, y Kuki Shuzô se encuentran entre los filósofos de mayor reputación que fueron a Alemania y adoptaron claramente la iniciativa neokantiana de la "Escuela de Baden". Pero, la influencia que autores como Dilthey, Windelband y Rickert ejercieron en el Japón de finales del XIX y principios del XX no se limitó a algunos intelectuales aislados, sino que fue notoria entre los más importantes círculos de discusión filosófica, ya que su pensamiento ayudaba a enfocar el planteamiento histórico-cultural hacia la estética más allá de las premisas del propio Hegel. Sin embargo, entre todos los autores, Dilthey (quien influenció directamente a Ônishi y a Nishida) fue el que ejerció mayor peso debido a su célebre diferenciación entre ciencias naturales y ciencias del espíritu, una distinción que a los japoneses

45 Heidegger no empezó a escribir sobre las artes sino hasta la llegada de los años treinta. Por lo tanto, el alcance de su influencia sobre los intelectuales japoneses interesados en la estética, que fueron a verlo durante los años veinte, es difícil de ser estimada. En particular porque, en un diálogo ficticio compuesto en 1954 bajo el título Aus einem Gespräch von der Sprache: zwischen einem Japaner und einem Fragenden (publicado en Unterwegs zur Sprache. Tubinga: Neske, 1959), donde quizás Heidegger recordaba las muchas conversaciones que mantuvo con los estudiantes japoneses (entre ellos Kuki quien estudió con él en 1927), el autor alemán muestra, sin embargo, poca confianza en un proyecto que considera "estéril" porque es derivado de la fusión entre una realidad no europea y una estética basada en la metafísica $(C f$. Heidegger (1959), p. 131 y 138). Por otro lado, Graham Parkes ha pretendido argumentar que la metodología empleada por Kuki en La Estructura de lo Iki se deriva directamente de la hermenéutica heideggeriana presente en Ser y Tiempo. Pero, el único lugar de la obra de Kuki en donde se menciona al entonces joven y desconocido Heidegger es en una nota al pie de página donde aparece junto a Husserl y Oskar Becker. Dicha nota tan sólo procura ayudar al lector a diferenciar entre los términos "formal" y kaishakuteki, esto es, la palabra utilizada en la época para traducir Deutung o "interpretación" (Cf. Tetsugaku Jiten. Tokio: Seikô Kanzô, 1938). Sin embargo, cuando en la conclusión del texto se hace explicito el fundamento interpretativo que sirvió de base para estudiar los fenómenos estéticos particulares de la cultura japonesa en la era Edo, Kuki lo describe usando la palabra propiamente traducida como "hermenéutica", esto es, kaishakugaku, la cual se encontraba en aquel tiempo directamente asociada con la figura de Dilthey. Cf. S. Kuki, Iki no Kôzô. Tokio: Iwanami Shoten, 1930, p. 15 y 143; G. Parkes, "Rising Sun over the Black Forest: Heidegger's Japanese connections" en R. May, Heidegger's Hidden Sources: East Asian Influences on His Work. Londres y Nueva York: Routledge, 1996, p. 93. Mi más profundo agradecimiento a Curtis Rigsby y a Eiho Baba por su imprescindible colaboración en la investigación de este intrincado asunto. 
les resultaba especialmente fácil de reconocer no sólo debido a sus contenidos diversos sino también por sus métodos diferenciados.

La "Escuela de Baden" también ayudó a los intelectuales japoneses a construir las fundaciones filosóficas para el estudio de las manifestaciones culturales del pasado y a la vez les proporcionó herramientas teóricas para reconocer los estilos comunes y unificados en el arte, la literatura y la religión de períodos históricos diversos. Esto se ve claramente manifiesto en las obras de Nishida, Okakura, Kuki, Ônishi, Suzuki, Watsuji, Hisamatsu y de todos aquellos autores que se comprometieron con la iniciativa de los estudios sobre la estética japonesa y consideraban una responsabilidad del filósofo de las artes la búsqueda de categorías estéticas propias, y no la simple adopción de términos occidentales para interpretar las artes tradicionales del Japón.

Ningún otro autor fue más consciente de la naturaleza de dicha iniciativa hermenéutica que Ônishi. Ônishi pertenece a la primera generación de intelectuales en Japón que fueron capaces de superar la tarea inicialmente intimidatoria de dominar las teorías estéticas de Occidente y, a la vez, lograron un acercamiento filosófico apropiado a la realidad japonesa. La dificultades de dicha tarea no deben ser subestimadas y la prueba de ello es que la labor intelectual de sus más afamados profesores quedó paralizada hasta el punto de que durante las tres primeras décadas en que la filosofía Occidental fue dada a conocer en Japón, la mayoría de ellos no pudieron escribir ni un solo libro sobre filosofía del arte ${ }^{46}$. Tendríamos que esperar a 1957, cuando Ônishi nos da un ejemplo en su Bigaku [Estética] de cómo, junto a muchos otros, había asumido el proyecto que sus profesores les habían encomendado sobre las siguientes bases: en primer lugar, "para estudiar exhaustivamente problemas de estética uno ha de reflexionar sobre la conciencia estética que ha avanzado en la dirección específica que puede denominarse oriental" para luego "hacer el esfuerzo de complementar el núcleo de la estética occidental con nuestros logros y entonces expandirla más allá de sus propios límites ${ }^{47}$.

El trabajo de Ônishi nos muestra cómo los esfuerzos investigadores de los filósofos modernos japoneses se desarrollaron desde las primeras tentativas de Nishi y Tsuda, quienes, como se vio, importaban y aplicaban categorías occidentales para definir Oriente, hasta llegar a los trabajos de principios del siglo $\mathrm{XX}$, cuando fueron producidas algunas de las mejores investigaciones en el área de la estética japonesa. Sin embargo, es importante señalar que, más allá del proyecto humanista de liberación cultural, dichas obras fueron también asimiladas con entusiasmo por el nacionalismo y militarismo extremo del Japón

46 M. Ueda en Rimer (1990), p. 285.

47 M. Yamamoto en M. Marra (2001), p. 173. 
de los años veinte y treinta y que, además, muchos autores mostraron una falta de claridad enigmática en el momento de distinguir entre el fanatismo nacionalista y la investigación cultural ${ }^{48}$. Con todo, no sería justo acusar a dichos trabajos de haberse dedicado maliciosamente a interpretar Japón como un "otro" radical sin mayor fin que la pura satisfacción etnocéntrica y no reconocer los esfuerzos sinceros por investigar su kyôyôshugi o Geist efectivamente mejor que en cualquier otra área de la filosofía.

En los escritos sobre estética la voz de estos intelectuales se manifiesta libre y hábil al discurrir acerca de su lugar de nacimiento. Gracias a ello, las reflexiones sobre estética tuvieron como consecuencia que un país que se sentía culturalmente subdesarrollado alcanzase una liberación cultural autoconsciente del sinsentido resultado del nihilismo que había sido adoptado indiscriminadamente de Occidente. El campo de la estética les permitió profundizar en sus propias determinaciones culturales $\mathrm{y}$, al mismo tiempo, sentirse asentados en los fundamentos teóricos de la filosofía alemana, la cual ha sido, desde entonces, la fiel compañera de un proyecto filosófico moderno que aún continúa enfrentándose al problema de la convivencia con la diversidad y el encuentro entre culturas.

48 Una excelente compilación de ensayos que profundiza sobre el tema y sus controversias es J.W. Heisig y J. Maraldo (ed.), Rude Awakenings: Zen, the Kyoto School and the Question of Nationalism. Honolulu: University of Hawai'i Press, 1994. 